\title{
Manajemen Pembinaan Prestasi Olahraga di Sekolah Khusus Olahragawan Internasional (SKOI) Kalimantan Timur
}

\author{
Suparno, Dwi Nugroho Hidayanto, Pm. Labulan \\ Universitas Mulawarman \\ suparnoikip@gmail.com
}

\begin{abstract}
Abstrak
Penelitian ini bertujuan untuk mengetahui bagaimana manajemen pembinaan prestasi olaharaga di Sekolah Khusus Olahragawan Internasional (SKOI) Kalimantan Timur. Penelitian ini menggunakan pendekatan kualitatif adalah suatu proses penelitian yang menghasilkan temuan yang diperoleh dari data-data yang dikumpulkan melalui teknik observasi partisipasi, wawancara mendalam dan studi dokumentasi dengan menggunakan model Miles Huberman. Hasil temuan penelitian ini menunjukkan bahwa: (1) Perencanaan, program pemassalan, pembibitan pembinaan prestasi olahraga dilakukan sejak dini (2) Pengorganisasian dilaksanakan dengan bekerjasama antara Pemerintah/Dinas Pendidikan Pemuda dan Olahraga Kalimantan Timur dan Sekolah Khusus Olahragawan Internasional Kalimantan Timur dalam pengadaan tenaga pelatih dan pendanaan (3) Pelaksanaan, rekrutmen sumber daya manusia dalam hal ini pelatih dan atlit telah terlaksana dengan baik dengan melalui tahapan pendaftaran, selaksi administrasi, tes tertulis tes praktik olahraga sampai program-program yang dibuat oleh pelatih sudah di koordinasikan dengan baik.
\end{abstract}

\section{PENDAHULUAN}

Pembinaan Sumber Daya Manusia adalah upaya berkesinambungan meningkatkan mutu sumber daya manusia dalam arti yang seluas-luasnya, melalui pendidikan, latihan dan pembinaan (Baris, $U$, (2013:34).Pembinaan merupakan suatu cara efektif untuk menghadapi beberapa tantangan yang dihadapi oleh banyak organisasi besar. Pembinaan adalah penyiapan individu untuk memikul tanggung jawab yang berbeda atau yang lebih tinggi di dalam organisasi (John, A, (2015:87). Pembinaan biasanya berhubungan dengan peningkatan kemampuan intelektual atau emosional yang diperlukan untuk menuaikan pekerjaan yang lebih baik. Prestasi di bidang olahraga dapat mengangkat nama baik olahraga, sekolah, daerah serta mengharumkan nama bangsa dan negara di dunia. Persaingan olahraga prestasi dewasa ini semakin ketat. Prestasi bukan lagi milik perorangan, tetapi sudah menyangkut harkat dan martabat suatu bangsa. Itulah sebabnya berbagai daya dan upaya dilakukan oleh suatu sekolah atau daerah, maupun negara untuk menempatkan atlitnya sebagai juara di kegiatan-kegiatan olahraga. Pembinaan olahraga merupakan sebuah tahap penting dalam mencapai prestasi olahraga. Namun banyak olahraga yang kurang memperhatikan hal ini, sehingga tidak dapat bersaing dalam hal prestasi maupun keberlangsungan latihan tidak terencana dengan baik, sistematis dan bertahan lama. Sistem pembinaan prestasi olahraga di Indonesia adalah pemanduan bakat dan pengembangan bakat. Jadi, untuk mencapai jenjang prestasi tinggi di butuhkan sistem pembinaan yang baik. Tanpa pembinaan yang tersistem dengan maksimal maka tahap pencapaian prestasi tidak akan tercapai.Selain itu seiring dengan perkembangan olahraga, olahraga juga digunakan sebagai sarana untuk mengangkat harkat dan martabat. Hal tersebut dapat dicapai melalui prestasi yang membanggakan dibidang olahraga. Untuk mencapai tujuan tersebut, di Indonesia telah ada satu organisasi keolahragaan nasional yang berwenang 
mengkoordinasikan dan membina setiap dan seluruh kegiatan olahraga prestasi. Organisasi yang dimaksud adalah Sekolah Khusus Olahragawan Internasional (SKOI) yang mempunyai tujuan untuk mewujudkan prestasi olahraga yang membanggakan, membangun watak bangsa untuk mengangkat harkat dan martabat bangsa Indonesia. Berdasarkan konteks penelitian peneliti tertarik untuk menganalisis tentang "Manajemen Pembinaan Prestasi Olahraga di Sekolah Khusus Olahragawan Internasional Kalimantan Timur".Berangkat dari fokus dan subfokus konteks di atas, yang akan dikemukakan di penelitian ini adalah Manajemen Pembinaan Prestasi Olahraga Di Sekolah Khusus Olahragawan Internasional Kalimantan Timur sebagai berikut: Bagaimana manajemen perencanaan pembinaan prestasi olahraga di Sekolah Khusus Olahragawan Internasional Kalimantan Timur?,Bagaimana manajemen pengorganisasian pembinaan prestasi olahraga di Sekolah Khusus Olahragawan Internasional Kalimantan Timur?,Bagaimana manajemen pelaksanaan pembinaan prestasi olahraga di Sekolah Khusus Olahragawan Internasional Kalimantan Timur?, Bagaimana manajemen pegawasan pembinaan prestasi olahraga di Sekolah Khusus Olahragawan Internasional Kalimantan Timur?. "TQM a philosophy and set of guilding principles that represent the foundation of a continuosly improving organization, include seven broad components. focus on the customer or user of a product or service, ensuring the customer's need an expectations are satisfied consistenly. Active leadership from executive to establish quality as fundamental value to be incorporated into a company's managemen philosophy. Quality concept (statistical process control or computer assisted design, engineering, and manufacturing) that are thoroughly integrated throughout al activities of or a company corporate culture, estabilshed and reinforced by top executives, that involves all employees in contributing to quality improvement. focus on employeed involvement, team work, and training at all levels in order to strengthen employee commitment to continous quality improvement. an approach to problem solving that is base on continously gathering, evaluating, and acting on facts and data is a systematic manner. Recognition of supliers as full partners in quality management process" McLelland, D.C, (2013:54) mengemukakan bahwa perencanaan ialah pemilihan dan penghubungan fakta-fakta serta perbuatan dan penggunaan pikiran-pikiran untuk masa yang akan datang dengan cara menggambarkan dalam merumuskan kegiatan-kegiatan yang diperlukan untuk mencapai hasil yang diinginkan. Sedangkan menurut Munandar, A, (2013:22) perencanaan merupakan proses yang sistematis dalam pengambilan keputusan tentang tindakan yang akan dilakukan pada waktu yang akan datang. Schwandt, D.R, (2014:17) Pelaksanaan pembinaan prestasi olahraga pada hakikatnya adalah proses kegiatan yang dilaksanakan oleh kepala sekolah atau seluruh kelompok yang berkepentingan atau pilihan mengenai program-program kegiatan atau sasaran mutu dan cara-cara yang akan dilaksanakan dimasa yang akan datang guna mencapai tujuan yang dikehendaki serta pemantauan dan penilaiannya atas hasil pelaksanaannya, yang dilaksanakan secara sistematis dan berkesinambungan. Proses ini ada lima kegiatan, yaitu: menilai situasi dan kondisi saat ini yang didasarkan pada hasil evaluasi diri sekolah, merumuskan dan menetapkan situasi dan kondisi yang diinginkan (yang akan datang), menentukan apa saja yang perlu dilakukan untuk mencapai keadaan yang diinginkan, mempersiapkan dan melaksanakan pemantauan dan penilaian atas hasil pelaksanaanya, serta dilaksanakan secara sistematis dan berkesinambungan. Didalam Undang-Undang Republik Indonesia nomor 3 tahun 2005 tentang Sistem Keolahragaan Nasional, pelaku olahraga merupakan sumber daya manusia bidang keolahragaan. Pelaku olahraga adalah setiap orang dan/kelompok yang terlibat secara langsung dalam kegiatan olahraga 
yang meliputi pengolahraga, pembina olahraga dan tenaga keolahragaan. Bab I pasal 1 menjelaskan beberapa hal mengenai sumber daya manusia bidang olahraga yaitu: 1) Pengolahraga adalah orang yang berolahraga dalam usaha mengembangkan jasmani, rohani dan sosial. 2) Olahragawan adalah pengolahraga yang mengikuti pelatihan secara teratur dan kejuaraan dengan penuh dedikasi untuk mencapai prestasi. 3) Pembina olahraga adalah orang yang memiliki minat dan pengetahuan kepemimpinan kemampuan manajerial atau pendanaan yang didedikasikan untuk kepentingan pembinaan dan pengembangan olahraga. 4) Tenaga keolahragaan adalah setiap orang yang memiliki kualifikasi dan sertifikat kompetensi dalam bidang olahraga. Setiap organisasi apapun bentuknya sanantiasa akan berupaya dapat tercapainya tujuan organisasi yang bersangkutan dengan efektif dan efisien. Efisiensi maupun efektivitas organisasi sangat tergantung pada baik buruknya pembinaan sumber daya manusia atau anggota organisasi itu sendiri, ini berarti bahwa sumber daya manusia yang ada dalam organisasi tersebut secara proporsional harus diberikan latihan dan pendidikan yang sebaik-baiknya, bahkan harus sesempurna mungkin. Pembinaan atlit yaitu upaya untuk memunculkan individu-individu bibit atlit berpotensi sehingga mampu mencapai prestasi maksimal dikemudian hari. Pembinaan yang dilakukan secara sistematik, tekun, dan berkelanjutan, diharapkan dapat mencapai hasil prestasi yang maksimal

\section{METODE PENELITIAN}

Penelitian ini menggunakan pendekatan kualitatif adalah suatu proses penelitian yang menghasilkan temuan yang diperoleh dari data-data yang dikumpulkan melalui teknik observasi partisipasi, wawancara mendalam dan studi dokumentasi dengan menggunakan model Miles Huberman, (2011:66). Metode studi kasus bertujuan untuk menjelaskan dan menganalisis mengenai Manajemen Pembinaan Prestasi Olahraga di Sekolah Khusus Olahragawan Internasional Kalimantan Timur.

\section{INSTRUMEN DAN PENGUMPULAN DATA}

Instrumen penelitian dalam disertasi ini adalah peneliti sendiri sebagai key instrument, sedangkan yang menjadi informan atau sumber data adalah Kepala Sekolah UPT, pengelola, Pelatih cabor, Pembina Olahraga, Atlit cabor di SKOI Kaltim sebagai informan penentuan informan (sumber data) dalam penelitian ini, peneliti menggunakan teknik purposive sampling, dimaksudkan bahwa informan yang diambil tidak dimaksudkan untuk mewakili populasi, melainkan untuk mewakili informasi yang dibutuhkan dalam penelitian ini.

\section{PROSEDUR DAN \\ PENGUMPULAN DATA}

Prosedur pengumpulan data dalam penelitian kualitatif melalui tahapan sebagai berikut : (1) The Sttage of Reflection (tahapan Refleksi), (2) The Stage of Planning (tahapan Perencanaan), (3) The Stage of Entry (Tahapan Memasuki Lapangan), (4) The Stage of Produktive Data Collection (Tahapan Pengumpulan Data), (5) The Stage of Withdrawal (Tahapan Penarikan Diri), dan (6) The Stage of Writing (Tahapan Penulisan Hasil Penelitian).

\section{PENGUJIAN KEABSAHAN DATA}

Teknik pengujian keabsahan pada penelitian kualitatif dapat dilakukan dengan beberapa cara, yaitu: (1) Uji Kredibility (validitas internal). (2) Uji Transferability (validitas eksternal), (3) Uji Dependability (reliabilitas), dan (4) Confirmability (obyektivitas). Pengujian krebilitas data kepercayaan terhadap data hasil penelitian kualitatif dapat dilakukan dengan triangulasi yaitu (1) Triangulasi metode atau tehnik dilakukan untuk menguji kredibilitas data dilakukan dengan cara mengecek data kepada sumber yang sama dengan tehnik yang berbeda. (2) Triangulasi sumber data adalah triangulasi yang digunakan untuk menguji kredibilitas data dengan cara mengecek data yang telah diperoleh melalui beberapa sumber dan (3) Triangulasi teori digunakan untuk 
membandingkan hasil akhir penelitian dengan perspektif penelitian yang relevan untuk menghindari bisa individual peneliti atas temuan atau kesimpulan.

\section{TEMUAN PENELITIAN DAN PEMBAHASAN}

Teknik Analisis Data

Setelah pengumpulan data dilakukan baik data primer maupun data sekunder, yang berhubungan dengan Manajemen Pembinaan Prestasi Olahraga di Sekolah Khusus Olahragawan Internasional Kalimantan Timur selanjutnya data tersebut diolah dan dianalisis sebagai berikut: (1) Analisis sebelum dilapangan yaitu analisis yang dilakukan terhadap data hasil studi pendahuluan atau data sekunder yang akan digunakan untuk menentukan fokus penelitian, dan (2) Analisis selama dilapangan (Model Milles and Huberman) yaitu dilakukan pada saat pengumpulan data berlangsung, dan setelah selesai pengumpulan data dalam priode tertentu. Aktivitas dalam analisis data meliputi: Data Collection, Data Reduction, Data Display dan Conclution Drawing/Verivication. Hasil temuan penelitian ini menunjukkan bahwa: (1) Perencanaan, program pemassalan, pembibitan pembinaan prestasi olahraga dilakukan sejak dini (2) Pengorganisasian dilaksanakan dengan bekerjasama antara Pemerintah/Dinas Pendidikan Pemuda dan Olahraga Kalimantan Timur dan Sekolah Khusus Olahragawan Internasional Kalimantan Timur dalam pengadaan tenaga pelatih dan pendanaan (3) Pelaksanaan, rekrutmen sumber daya manusia dalam hal ini pelatih dan atlit telah terlaksana dengan baik dengan melalui tahapan pendaftaran, selaksi administrasi, tes tertulis tes praktik olahraga sampai program-program yang dibuat oleh pelatih sudah di koordinasikan dengan baik, Pemilihan atlit berbakat dan pembinaan prestasi atlit berkelanjutan di Sekolah Khusus Olahragawan Internasional Kalimantan Timur melalui beberapa tahapan yaitu pemassalan, usia 612 tahun (atlit pemula), pembibitan usia spesialisasi adolesensi usia 13-18 tahun (junior lanjut) pembinaan prestasi puncak pasca adolesensi usia 18 tahun ke atas (atlit senior), kualifikasi pelatih telah sesuai dengan keahlian dan pengalaman yang dimiliki seorang pelatih dalam setiap cabang olahraga, sarana dan prasarana yang dimiliki Sekolah Khusus Olahragawan Internasional Kalimantan Timur sangat lengkap karena memfaatkan fasilitas pasca PON 2008 dan sangat mendukung program-program latihan yang diterpkan oleh pelatih, (4) Pengawasan di Sekolah Khusus Olahragawan Internasional Kalimantan Timur melibatkan lembaga Dinas Pendidikan Pemuda dan Olahraga Kalimantan Timur dan manajemen pembinaan prestasi atlit berkontribusi menjadi model pembinaan cabang olahraga dalam membangun prestasi olahraga di Sekolah Khusus Olahragawan Internasional Kalimantan Timur. Menjadi solusi/barometer bagi maju dan mundurnya prestasi olahraga di Kalimantan Timur pada khususnya dilakukan pembinaan lanjut setelah lulus dari sekolah khusus olahragawan internasional Kalimantan Timur untuk prestasi puncak usia 18 tahun setelah lulus dari SKOI.

\section{PEMBAHASAN}

\section{Perencanaan Manajemen \\ Pembinaan Prestasi Olahraga}

Perencanaan program pemassalan prestasi olahraga sudah dilakukan sejak dini, perencanaan olahraga disesuaikan dengan visi dan misi SKOI Kaltim yaitu menyiapkan Sumber Daya Manusia (SDM) yang unggul dan berprestasi di bidang olahraga dan akademik berdasarkan intelektualitas, berwawasan iptek serta berwasawan IMTAQ, strategi perencanaan atlit sudah diprogramkan pembinaan yang disusun oleh pelatih, penyusunan program kerja, perencanaan pembinaan prestasi perencanaan anggaran, perencanaan sarana dan prasarana. Strategi dalam perencanaan program pengembangan sumber daya manusia dalam hal ini pelatih melalui pelatihan. Sedangkan bentuk kegiatan yang direncanakan untuk:1) Meningkatkan pengetahuan dan wawasan pelatih adalah 
pelatihan, workshop, dengan pelatihpelatih dilingkungan sendiri. 2) Pembentukan sikap dan komitmen pelatih melalui studi banding pelatihan daerah dan pemusatan pelatihan nasional baik antara atlit daerah maupun atlit nasional. Mengenai hasil perencanaan program pengembangan sumber daya manusia yang telah disusun di sekolah selanjutnya dimatangkan dalam keputusan rapat. Perencanaan program pengembangan pembinaan prestasi olahraga atlit dalam suatu lembaga pelatihan jika dilakukan dengan proses yang benar, memberikan manfaat jangka panjang yang maksimal untuk mendapatkan prestasi dijenjang nasional perlu perencanaan yang berkualitas dengan jumlah yang tepat dan jenis orang yang tepat, di tempat yang tepat dan pada waktu yang tepat.

\section{Pengorganisasian Manajemen \\ Pembinaan Prestasi Olahraga}

Dilakukan untuk menghimpun sumber daya yang dimiliki oleh Sekolah Khusus Olahragawan Internasional Kaltim dan memberdayakannya secara efektif. Dalam perorganisasian program pembinaan prestasi olahraga atlit di Sekolah Khusus Olahragawan Internasional Kaltim, Kepala Sekolah Khusus Olahragawan Internasional Kaltim melakukan pengorganisasian sebelum pelaksanaan pembinaan prestasi olahraga melalui pembentukan panitia dengan pembagian tugas dan tanggung jawab terhadap kegiatan yang akan dilaksanakan. Koordinasi dan kerjasama pengurus, pembinaan prestasi olahraga, pihak SKOI Kaltim bekerjasama dengan Dinas Pendidikan Pemuda dan Olahraga Kalimantan Timur Kaltim dalam mengadakan pelatih, Sekolah Khusus Olahragawan Internasional Kalimantan Timur berkoordinasi dengan daerah-daerah untuk menjaring bibit-bibit atlit yang memiliki potensi untuk berprestasi, pihak Sekolah Khusus Olahragawan Internasional Kalimantan Timur bekerjasama dengan Dinas Pendidikan
Pemuda dan Olahraga Kalimantan Timur dalam mengadakan dana baik yang berasal dari APBN dan APBD.

\section{Pelaksanaan Manajemen Pembinaan Prestasi Olahraga}

Pelaksanaan rekrutmen sumber daya manusia dalam hal ini pelatih dan atlit, telah terlaksana dengan baik karena adanya perencanaan dan pengorganisasian yang baik. Pelaksanaaan rekrutmen pelatih, sepenuhnya dilaksanakan oleh Sekolah Khusus Olahragawan Internasional Kalimantan Timur dengan melalui tahapan, pendaftaran, seleksi administrasi, tes tertulis dan tes praktik olahraga sampai penetapan pelatih yang di terima. Frekuensi rekrutmen pada umumnya dilaksanakan satu kali dalam setahun yaitu pada awal tahun, tapi terkadang juga ketika pelatih ada yang pindah keluar daerah, maka pengelola berkoordinasi dengan pihak Dinas Pendidikan Pemuda dan Olahraga Kalimantan Timur mencari penggantinya dengan melaksanakan rekrutmen secara emergency. Survey menemukan bahwa pelaksanaan perekrutan dan pemberian kompensasi (imbalan) yang inovatif dalam suatu pelatihan memiliki hubungan positif yang signifikan dengan peningkatan kinerja sumber daya atlit dan pelatih. Strategi pelaksanaan pembinaan prestasi atlit dilaksanakan mengikuti program-program yang sudah disetujui Dinas Pendidikan Pemuda dan Olahraga Kalimantan Timur/ Sekolah Khusus Olahragawan Internasional Kalimantan Timur yang dirancang oleh pelatih disetiap cabor, pelaksanaan kegiatan pelatihan merupakan kewajiban yang harus dilaksanakan oleh atlit dibawah bimbingan pelatih yang memiliki kualifikasi dan pengalaman sebagai atlit berstandar nasional dan internasional, pelaksanaan terjadwal di dalam program dan disesuaikan dengan tingkat prioritas event-event kejuaraan yang akan diikutkan disetiap cabor yang ada di Sekolah Khusus Olahragawan Internasional Kalimantan Timur, pelaksanaan melibatkan pelatih-pelatih yang sudah disiapkan pihak Dinas Pendidikan Pemuda dan Olahraga 
Kalimantan Timur dengan sistem kontrak dan level pendidikan dan pengalaman kualifikasi yang dimiliki oleh pelatih, pemilihan atlit berbakat dan pembinaan prestasi olahraga, atlit berkelanjutan di Sekolah Khusus Olahragawan Internasional Kalimantan Timur dilaksanakan melalui beberapa tahapan yaitu pemassalan, usia 6-12 tahun Sekolah Dasar mulai berolahraga (pemula), pembibitan usia spesialisasi masa Adolesensi usia 13-18 tahun (junior lanjut), pembinaan prestasi usia pencapaian prestasi puncak, pasca adolesensi 18 tahun ke atas atlit senior, perekrutan pelatih berdasarkan kriteria; ijazah sesuai dengan keahlian yang dimiliki, pengalaman atlit senior sesuai dengan cabang olahraga yang pernah diikutinya, Sekolah Khusus Olahragawan Internasional Kalimantan Timur memiliki fasilitas lengkap karena memanfaatkan fasilitas pasca PON 2008 sehingga menjadi rujukan sekolah khusus olahragawan internasional di Indonesia. Sarana dan prasarana yang dimiliki sangat mendukung atlit dalam latihan di setiap cabor dan memudahkan pelatih dalam memanfaatkan fasilitas dalam pembinaan prestasi atlit di Sekolah Khusus Olahragawan Internasional Kalimantan Timur.

\section{Pengawasan Manajemen Pembinaan Prestasi Olahraga}

Pengawasan yang dilakukan oleh Sekolah Khusus Olahragawan Internasional Kalimantan Timur dimaksudkan agar pelaksanaan pekerjaan sesuai instruksi yang telah dikeluarkan, dan untuk mengetahui kelemahan-kelemahan serta kesulitan-kesulitan yang dihadapi dalam pelaksanaan rencana berdasarkan temuantemuan tersebut sehingga dapat diambil tindakan untuk memperbaiki baik pada waktu itu maupun pada waktu yang akan datang SKOI Kaltim melibatkan lembaga Dinas Pendidikan Pemuda dan Olahraga Kalimantan Timur dalam hal pengawasan akademik dan non akademik yang bekerjasama dan Dinas Kesehatan mengenai mental dan anatomi tubuh atlit.

\section{Evaluasi Manajemen Pembinaan Prestasi Olahraga}

Context Latar belakang dari masalah manajemen baik, namun untuk masalah anggaran dan prestasi masih cukup. Perencanaan pembentukan tim dan perencanaan program manajemen sudah baik, namun perencanaan untuk juara cukup. Input, Penyebaran informasi dilakukan dengan baik, yaitu melalui cabor-cabor, media elektronik dan media massa serta pengurus kelompok supporter, Tempat latihan sudah tersedia, sudah mempunyai asrama atlit dengan kondisi yang lengkap dan memadai. Dukungan pemerintah hanya pada kebijakan dan dorongan. Masyarakat baik antusias dalam memberikan dukungan. SDM sudah mendukung terlaksananya pembinaan prestasi di SKOI Kaltim. Process, Program latihan berjalan dengan baik. Kontrol pelaksanaan program latihan sudah baik. Evaluasi program latihan berjalan dengan baik. Atlit selalu mengikuti kompetisi Liga Indonesia. Koordinasi antara pengurus dengan pemerintah, atlit dengan pelatih dan pengurus dengan pelatih sudah berjalan dengan baik. Seleksi penerimaan atlit sudah dilakukan dengan baik dan selektif seperti faktor usia, potensi atlit, postur tubuh, dan komponen biomotorik. Seleksi pelatih dan asisten pelatih sudah baik seperti lisensi pelatih dan pembuatan program latihan. Tempat latihan yang digunakan sudah baik dan memadai. Product. Hasil program pembinaan masih cukup, namun sampai saat ini SKOI sudah mempunyai prestasi di level sepakbola nasional.

\section{SIMPULAN DAN REKOMENDASI}

Berdasarkan hasil analisis pembahasan temuan tentang Manajemen Pembinaan Prestasi Olahraga di Sekolah Khusus Olahragawan Internasional (SKOI) Kalimantan Timur, dapat ditarik simpulan dan rekomendasi sebagai berikut:

\section{Simpulan}

1. Perencanaan manajemen pembinaan prestasi olahraga melalui Perencanaan program pemassalan prestasi olahraga sudah dilakukan sejak dini, perencanaan olahraga disesuaikan 
dengan visi dan misi Sekolah Khusus Olahragawan Internasional Kalimantan Timur yaitu menyiapkan sumber daya manusia (SDM) yang unggul dan berprestasi di bidang olahraga dan akademik berdasarkan intelektualitas, disiplin tinggi berwawasan iptek serta berwawasan IMTAQ, strategi perencanaan atlit sudah diprogramkan dalam pembinaan yang disusun oleh pelatih, penyusunan program kerja.

2. Pengorganisasian dilakukan untuk menghimpun sumber daya yang dimiliki oleh Sekolah Khusus Olahragawan Internasional Kalimantan Timur dan memberdayakannya secara efektif. Dalam perorganisasian program pembinaan prestasi olahraga atlit di Khusus Olahragawan Internasional Kalimantan Timur, Kepala Sekolah Khusus Olahragawan Internasional Kalimantan Timur melakukan pengorganisasian sebelum pelaksanaan pembinaan prestasi olahraga melalui pembentukan panitia dengan pembagian tugas dan tanggung jawab terhadap kegiatan yang akan dilaksanakan. Koordinasi dan kerjasama pengurus, pembinaan prestasi olahraga, pihak Sekolah Khusus Olahragawan Internasional Kalimantan Timur bekerjasama dengan Dinas Pendidikan Pemuda dan Olahraga Kalimantan Timur dalam mengadakan pelatih, Sekolah Khusus Olahragawan Internasional Kalimantan Timur berkoordinasi dengan daerah-daerah untuk menjaring bibit-bibit atlit yang memiliki potensi untuk berprestasi, pihak Sekolah Khusus Olahragawan Internasional Kalimantan Timur bekerjasama dengan Dinas Pendidikan Pemuda dan Olahraga Kalimantan Timur dalam mengadakan dana baik yang berasal dari APBN dan APBD.

3. Pelaksanaan pemilihan atlit berbakat dan pembinaan prestasi atlit berkelanjutan di Sekolah Khusus Olahragawan Internasional Kalimantan Timur dilaksanakan melalui beberapa tahapan yaitu pemassalan, usia 6-12 tahun Sekolah Dasar mulai berolahraga (pemula), pembibitan usia spesialisasi masa Adolesensi usia 13-18 tahun (junior lanjut), pembinaan prestasi usia pencapaian prestasi puncak, pasca adolesensi 18 tahun ke atas atlit senior. Kualifikasi pelatih, seleksi pengadaan pelatih dilakukan oleh Dinas Pemuda dan Olahraga bekerja sama dengan Sekolah Khusus Olahragawan Internasional Kalimantan Timur. Perekrutan pelatih berdasarkan kriteria; ijazah sesuai dengan keahlian yang dimiliki, pengalaman atlit senior sesuai dengan cabang olahraga yang pernah diikutinya. Sarpras di Sekolah Khusus Olahragawan Internasional Kalimantan Timur memiliki fasilitas lengkap karena memanfaatkan fasilitas pasca PON 2008 sehingga menjadi rujukan sekolah khusus olahragawan internasional di Indonesia. Sarana dan prasarana yang dimiliki sangat mendukung atlit dalam latihan di setiap cabor dan memudahkan pelatih dalam memanfaatkan fasilitas dalam pembinaan prestasi atlit di Sekolah Khusus Olahragawan Internasional Kalimantan Timur.

4. Pengawasan yang dilakukan oleh Sekolah Khusus Olahragawan Internasional Kalimantan Timur dimaksudkan agar pelaksanaan pekerjaan sesuai instruksi yang telah dikeluarkan, dan untuk mengetahui kelemahan-kelemahan serta kesulitankesulitan yang dihadapi dalam pelaksanaan rencana berdasarkan temuan-temuan tersebut sehingga dapat diambil tindakan untuk memperbaiki baik pada waktu itu maupun pada waktu yang akan datang Sekolah Khusus Olahragawan Internasional Kalimantan Timur melibatkan lembaga Dinas Pendidikan Pemuda dan Olahraga Kalimantan Timur dalam hal pengawasan baik akademik dan non akademik yang bekerjasama dengan dinas pendidikan Kaltim, pihak Sekolah Khusus 
Olahragawan Internasional Kalimantan Timur bekerjasama dengan dinas kesehatan mengenai mental dan anatomi tubuh atlit.

5. Evaluasi manajemen pembinaan prestasi olahraga di Sekolah Khusus Olahragawan Internasional Kalimantan Timur.

a. Context. Latar belakang dan perencanaan program pembinaan prestasi sepakbola SKOI Kaltim sudah cukup baik karena dari masalah manajemen, perencanaan pembentukan tim dan perencanaan program manajemen sudah baik.

b. Input. Penyebaran informasi sudah dilakukan dengan baik. Tempat latihan sudah tersedia dan cabor sudah mempunyai asrama atlit. Masyarakat cukup antusias dalam memberikan dukungan dan SDM yang ada sudah mendukung terlaksananya pembinaan prestasi sepakbola SKOI Kaltim. Namun peralatan latihan memadai dan dukungan pemerintah masih perlu ditingkatkan lagi untuk mencapai keberhasilan pembinaan prestasi sepakbola SKOI Kaltim.

c. Process. Pelaksanaan program latihan, koordinasi, seleksi penerimaan atlit, pelatih dan asisten pelatih sepakbola di SKOI Kaltim dapat berjalan dengan baik serta tempat latihan yang digunakan untuk cabor sepakbola sudah baik.

d. Product. Prestasi yang dicapai sepakbola SKOI Kaltim kurang maksimal karena selama lima tahun terakhir belum mampu meraih gelar juara dalam kancah sepakbola nasional

\section{Rekomendasi}

Berdasarkan hasil pembahasan pada babbab sebelumnya disampaikan rekomendasi untuk perbaikan dan penyempurnaan manajemen pembinaan prestasi olahraga kepada pihak-pihak yang terkait, sebagai berikut:

1. Universitas Mulawarman Samarinda Kalimantan Timur.
Manajemen Pembinaan Prestasi

Olahraga di Sekolah Khusus Olahragawan Internasional Kalimantan Timur, penelitian ini diharapkan dapat menambah ilmu pengetahuan khususnya pada manajemen pembinaan prestasi atlit melalui peranan pelatih dalam proses pembinaan berkelanjutan di Sekolah Khusus Olahragawan Internasional Kalimantan Timur. Pola partisipasi atlit dalam mendukung program latihan pelatih hingga mencapai puncak prestasi. Peranan kebijakan Pemerintah/Dinas Pendidikan Pemuda dan Olahraga Kalimantan Timur dalam pelaksanaan pembinaan prestasi olahraga berkait dengan penghargaan dan bantuan. Implikasi manajemen pembinaan prestasi atlit melalui peranan pelatih dalam proses pembinaan berkelanjutan di Sekolah Khusus Olahragawan Internasional Kalimantan Timur.

2. Dinas Pendidikan Pemuda dan Olahraga Kalimantan Timur

Sebagai bahan pembinaan atlit dan pelatih Sekolah Khusus Olahragawan Internasional Kalimantan Timur. Sebagai masukan pemikiran bagi seluruh komponen sekolah khusus olahraga internasional seperti;

a. Pengelola; sebagai salah satu pertimbangan dalam memajukan prestasi olahraga di Sekolah Khusus Olahragawan Internasional Kalimantan Timur untuk menghasilkan atlit-atlit berprestasi baik di tingkat Nasional maupun Internasional.

b. Pelatih; sebagai pedoman pelatih untuk melaksanakan program latihan yang sesuai dengan pendekatan metode dan teori sehingga dapat meningkatkan prestasi olahraga.

c. Atlit; sebagai salah satu tolak ukur untuk membantu meningkatkan kemampuan dalam olahraga serta atlit dapat mengetahui hambatan dan kesulitan pengurus dan pelatih dalam melakukan pembinaan prestasi. 
d. Peneliti; hasil penelitian ini diharapkan dapat menambah pengetahuan dan pengalaman secara praktis dan acuan bagi peneliti berikutnya.

\section{DAFTAR PUSTAKA}

Bompa, (2014). Theory and Methodology of Training: The key to Athletic Performance. Thid edition. Iowa: Kendal/Hunt

Bunga R, (2014). Manajemen Olahraga. Cetakan ke-2. Penerbit PT. Sinar Harapan

Calhoun, $W$, (2013). Sport Culture and personality. Second edition Illinois: Human kinetics, Publisher, Inc.

Calhoun,W, 2011). Coaching Sport Management in Organization : A. review of theory and research. Internasional Journal of Managemen reviews.

Corrigen, J, (2012). Coaching Sport: Rhetoric or reality? Journal of Higher Educational Policy and Management Reviw. Vol. 13

Cresswell. J.W, (2013). Qualitative Inquary and Research Design Choosing Among Five Traditions . London \& New Delhi: Sage Publications.

Denis, J.L., Lamothe, L., \& Langley, A, (2012). The dynamicsof collective leadership and strategic change in pluralistic organization. Academicof management Journal. 44. Pp. 809-837.

Djahiri,A.K, Ahmad dan Wahab A. Azis, (2016). Dasar dan Konsep Pendidikan Moral. Jakarta: Depdikbud. Direktorat Jenderal Pendidikan Tinggi. PPTA.

Goleman, D, (2017). Quality Management Intelligence. Terjemahan. Jakarta: Gramedia Pustaka Utama.
Gunarsa, S.d, (2016) Psikologi Olahraga: Teori dan Praktek. Jakarta BPK Gunung Mulya.

Gunarsa, S.d., Satiadarma,M.P., dan Soekasah, M.H.R. (2016). Psikologi Olahraga: Teori dan praktek. Jakarta: Gunung Mulia.

Harre, D, (2012). Principles of Sport Training: Introduction to The Theory and Methods of Training. Berlin: Sportverlag.

Hall, D,.J.,Gunter, H., \& Bragg, J, (2013) The strange case of the emergence of coaching sport in schools in England. Journal Routledge Taylor \& Francis Group, Vol. 65, No.4.467-487.

Hall, D,.J.,Gunter, H., \& Bragg, J, (2012) Coaching Sport: Implications for the role of the principal. Journal of management development, 31 (1), 7-17.

Hall, D,.J.,Gunter, H., \& Bragg, J, (2010) Coaching Sport: Implications for the role of the principal. Journal of management development, 31 lss, 7-17.

Hall, D,.J.,Gunter, H., \& Bragg, J, (2011) Coaching Sport: Conceptual confusion and empirical reticence International Journal of Leadership in Education, 10 (3).

Harttley, D, (2016). The emergence of Coaching Sport in education: Why now? British Journal of Education Studies, pp. 202-214.

Hallinger, P, (2012). School Effectiveness and school Improvement Leadership \& Management, Journal An International Journal of Research, Policy and Pracitice. Vol. 2: No.461-4482. 
Jones, M., \& Harris, A, (2016). Principals leading Succesfull organizing, organizational change: Buliding social capital through disciplinn professional collaboration. Emerald Group publishing Limited Vol 27 No. 3 473-485.

Jones, S, (2015) Coaching Sport: A critical analysis. first published. Research article. Vol 10 Issue 2, 2015.

John, A, (2015). Membangun sportivitas atlit: mempersiapkan Generasi Anti Kecurangan. Portico Publishing, Surabaya.

Kemenegpora, (2015). Undang-undang Republik Indonesia no 3 Tahun 2005 Tentang Sistem Keolahragaan Nasional. Jakarta :Biro Humas dan Hukum.

Kuswarno, E, (2015). Fenomeology: Pedoman dan Contoh penelitian. Widya Pajajaran.

La Sunu, (2016) Disertasi Manajemen Sekolah Khusus Olahragawan Kalimantan Timur.

Lichtman, M, (2016). Review of: Qualitative research in education: A user's guide. $2^{\text {nd }}$ ed. Los Angleles, CA: Sage, 2010. Pp. xxi, 265. $\$ 49.95$, paper. ISBN978-1-41297052-5.

Lincoln, Y.S., dan , E,G. Guba, (2015)

Naturalisticc inquary. London: Sage

Lickona, T, (2012). Educating for sport, How Our schools can Teach Respect and responsibility. New York: Bantam Books.

Lutan, R, (2013). Olahraga Kebijakan dan Politik; Sebuah Analisis. Proyek Pengembangan \& Keserian Kebijakan Olahraga. Dirjen Olahraga Departemen Pendidikan Nasional.
Morris, M. E, (2016). School and drill practice and the job satisfaction of novice teachers: The influence of coaching sport. Boston College, ProQuest Dissertations Publishing, 2016. 1010220.

Lutan dan Mutohir, (2011).Olahraga dan pembinaan prestasi. di Lutan, R.(ed) (2011) Olahraga dan Etika Fair Play Jakarta: Direktorat Pemberdayaan Ilmu Pengetahuan dan Teknologi Olahraga Direktorat Jenderal Olahraga Departemen Pendidikan Nasional.

Maslow, A. H, (2013). Motivation and Personality, sari terjemahan (2014). PT.Garmedia . Jakarta.

Miles, M.B., dan A.M. Huberman, (2014) Qualitative Data Analysis. Second Edition. London: Sage. 